\title{
Alkali-activation of cellulose nanofibrils to facilitate surface chemical modification under aqueous conditions
}

\author{
Shingo Yokota, Airi Nishimoto and Tetsuo Kondo * (1)
}

\begin{abstract}
In this study, we developed a surface-activation technique for cellulose nanofibrils (CNFs) using mild-alkali and aqueous conditions. CNFs were initially processed using the aqueous counter collision (ACC) method to produce Janustype amphiphilic CNFs with both hydrophilic and hydrophobic faces on the surface of a single nanofibril (ACC-CNF). Selective functionalization of the hydroxy groups on the hydrophilic faces creates an opportunity to develop novel nano-building blocks that introduce heterogeneous and tailored surface characteristics into the design of nanomaterials. In this study, alkaline conditions were used to activate the hydroxy groups on the surface of ACC-CNFs as a pretreatment for the partial crystalline transformation from cellulose I to cellulose II. We found that alkali treatment with sodium hydroxide $(\mathrm{NaOH})$ solutions (concentration range 1-7 wt\%) did not fully transform the structure of ACC-CNFs into cellulose II, nor change the morphology of nanofibrils, as seen from their wide-angle X-ray diffraction patterns and atomic force microscopy images. We also found that the hydroxy groups at the surface region of the ACC-CNFs were sufficiently reactive under the moderate alkali and aqueous conditions to undergo subsequent carboxymethylation. Therefore, alkali treatment of ACC-CNFs with a 1-7 wt\% NaOH solution rendered the surface of the ACC-CNFs as sufficiently reactive for chemical modification without morphological changes. This simple method for surface activation of CNFs can be useful in the development of future sustainable and novel materials for a variety of applications.
\end{abstract}

Keywords: Cellulose nanofibrils, Aqueous counter collision, Alkaline surface activation

\section{Introduction}

In nature, the hierarchical self-organization of molecular or nano-scale building blocks can result in the formation of three-dimensional structures with unique properties and functions $[1,2]$. Synthetic amphiphilic substances, including low molecular weight surfactants [3], polymers [4] and nano-objects [5] can also be fabricated into functional materials with higher ordered structures. The interfacial interaction between the building blocks is an important factor in the bottom-up synthesis of these higher ordered structures. In particular, the surface properties of the building blocks should be closely related to

*Correspondence: tekondo@agr.kyushu-u.ac.jp

Graduate School of Bioresource and Bioenvironmental Sciences, Kyushu

University, West 5th, 744, Motooka, Nishi-ku, Fukuoka 819-0395, Japan those of the target hierarchical structure to successfully fabricate.

Cellulose microfibrils are important building blocks in nature and are integral in the formation of plant cell walls. Nowadays, cellulose microfibrils and their bundles are capable to be extracted as cellulose nanofibrils (CNFs) by methodological developments of nano-refining of pulp fibers [6]. The unique properties of CNFs, with their large specific surface areas [6], mechanical properties [7] and thermal stabilities [8], and their natural role as a biobased nano-building block, make them suitable materials in the fabrication of functional higher order structures.

Kondo et al. developed the aqueous counter collision (ACC) method as a nano-pulverization process [9, 10] that extracts nano-objects from a variety of natural resources. When raw cellulosic material in an aqueous
Springer Open
C The Author(s) 2022. Open Access This article is licensed under a Creative Commons Attribution 4.0 International License, which permits use, sharing, adaptation, distribution and reproduction in any medium or format, as long as you give appropriate credit to the original author(s) and the source, provide a link to the Creative Commons licence, and indicate if changes were made. The images or other third party material in this article are included in the article's Creative Commons licence, unless indicated otherwise in a credit line to the material. If material is not included in the article's Creative Commons licence and your intended use is not permitted by statutory regulation or exceeds the permitted use, you will need to obtain permission directly from the copyright holder. To view a copy of this licence, visit http://creativecommons.org/licenses/by/4.0/. 
suspension is subjected to the ACC method, specific intermolecular interactions are cleaved by the water collision energy propagated throughout the sample, generating single CNFs (ACC-CNFs) dispersed in water $[10$, 11]. The size and morphology of the resulting ACCCNFs is dependent on the starting raw material [10-12]. Using the ACC method ensures that both hydrophilic and hydrophobic planes, which are contained in natural cellulose crystals, are exposed on the surface of single ACC-CNFs [13]. Therefore, ACC-CNFs exhibit unique "Janus-type" amphiphilic surface properties [13], including switchable surface wettability [14], functioning that facilitates the formation of Pickering emulsions [12, 15] and adsorption onto hydrophobic polymer particles [16]. We recently reported that the surface properties of ACCCNFs can be altered via a simple process using oil droplets in a Pickering emulsion as a reaction platform [17, 18]. In this way, the surface amphiphilicity of the initial ACC-CNFs can be controlled to fabricate higher order architectures with novel functionalities.

Generally, the surfaces of crystalline cellulose are chemically resistant [19] and therefore, surface activation of the CNFs is required to add further functionality. Ideally, surface activation should be achieved using an environmentally friendly process with low energy requirements and non-toxic reagents. Ball milling is a commonly used approach for activating and chemically modifying the surfaces of cellulose fibers in a solvent-free system $[20,21]$. For aqueous dispersions, alkali treatments can enhance the chemical reactivity of cellulosic materials by removing hemicellulose and lignin, as well as by altering the crystallinity and the sporadic breaking of hydrogen bonds [20, 22, 23].

We have focused on the prospect of ACC-CNFs having unique surface properties as a nano-building block. In the initial step for facile modification of the surface, this study attempts to activate the hydroxy group on the surface of ACC-CNFs while maintaining their crystallinity of the fiber shape under moderate alkaline conditions using low concentrations of aqueous sodium hydroxide $(\mathrm{NaOH})$. Then, carboxymethylation, a method for ether derivatization, was conducted as an example of postchemical modification of ACC-CNFs.

\section{Experimental \\ Materials}

The starting material for preparing the ACC-CNFs was microcrystalline cellulose (MCC, Funacel $\mathrm{II}^{\circledR}$, Funakoshi Co., Ltd., Tokyo, Japan). MCC powder was rinsed with excess water and ethanol prior to ACC treatment, as implemented in previous studies $[15,24] . \mathrm{NaOH}$, chloroacetic acid and hydrochloric acid were purchased from FUJIFILM Wako Pure Chemical Corp., Osaka, Japan. Potassium bromide $(\mathrm{KBr})$ was purchased from Sigma-Aldrich Japan LLC., Tokyo, Japan. All chemical reagents were used as received without further purification. Deionized (DI) water was used for all experimental procedures.

\section{Preparation of cellulose nanofibrils (ACC-CNFs)}

An aqueous suspension of pre-rinsed MCC (1.0 wt\%) was treated using an ACC system (CNNT Co., Ltd., Incheon, South Korea) equipped with nozzles $160 \mu \mathrm{m}$ in diameter. The ACC treatment was repeated for 60 cycles at an ejecting pressure of $200 \mathrm{MPa}$. To remove micrometer-scale residues, the concentration of the ACC-CNF dispersion was diluted to $0.4 \mathrm{wt} \%$ and then centrifuged $\left(370 \times g, 10 \mathrm{~min}, 25^{\circ} \mathrm{C}[10]\right)$.

\section{Alkali treatment of ACC-CNFs}

All dispersions and solutions were heated at $60{ }^{\circ} \mathrm{C}$ for $30 \mathrm{~min}$ prior to mixing. Typically, $10 \mathrm{~g}$ of an aqueous ACC-CNF dispersion (0.2 $\mathrm{wt} \%$ ) was mixed with $5 \mathrm{~g}$ of an aqueous $\mathrm{NaOH}$ solution. The mixtures were then stirred at. As a result, the final concentrations of $\mathrm{NaOH}$ in the aqueous mixtures ranged from of $1-20 \mathrm{wt} \%$. The initial MCC powders prior to ACC treatments $(0.02 \mathrm{~g})$ were stirred in $1-20 \mathrm{wt} \% \mathrm{NaOH}$ aqueous solutions at $60^{\circ} \mathrm{C}$ for $1 \mathrm{~h}$.

\section{Surface carboxymethylation}

The alkali-treated ACC-CNFs were collected as a precipitate by centrifugation $\left(1500 \times g, 10 \mathrm{~min}, 25^{\circ} \mathrm{C}\right)$. An aqueous solution of chloroacetic acid was added to the still wet samples. The final concentration of chloroacetic acid in the mixture was adjusted to $20 \mathrm{wt} \%$. The mixture was then stirred at $45^{\circ} \mathrm{C}$ for $4 \mathrm{~h}$ [25]. The reaction media were displaced with DI water by centrifugation $(1500 \times g$, $10 \mathrm{~min}, 25^{\circ} \mathrm{C}$ ) to obtain the precipitated product.

\section{Wide-angle X-ray diffraction (WAXD) measurement}

As outlined above, after each alkali treatment, the alkaline media were exchanged with DI water by repeated centrifugation and re-dispersion, until reaching neutral $\mathrm{pH}$ 7.0. Neutralized samples were freeze-dried ready for wide-angle X-ray diffraction (WAXD) measurements (RINT 2000 V or SmartLab, Rigaku Corp., Tokyo, Japan). The WAXD profiles were acquired using Ni-filtered CuKa radiation $(\lambda=0.1542 \mathrm{~nm})$ at $40 \mathrm{kV}$ and $20 \mathrm{~mA}$ in $5-40^{\circ}$ of $2 \theta$. The scan rate and step were $0.5-2^{\circ} \mathrm{min}^{-1}$ and $0.05^{\circ}$, respectively. Carboxymethylated ACC-CNFs 

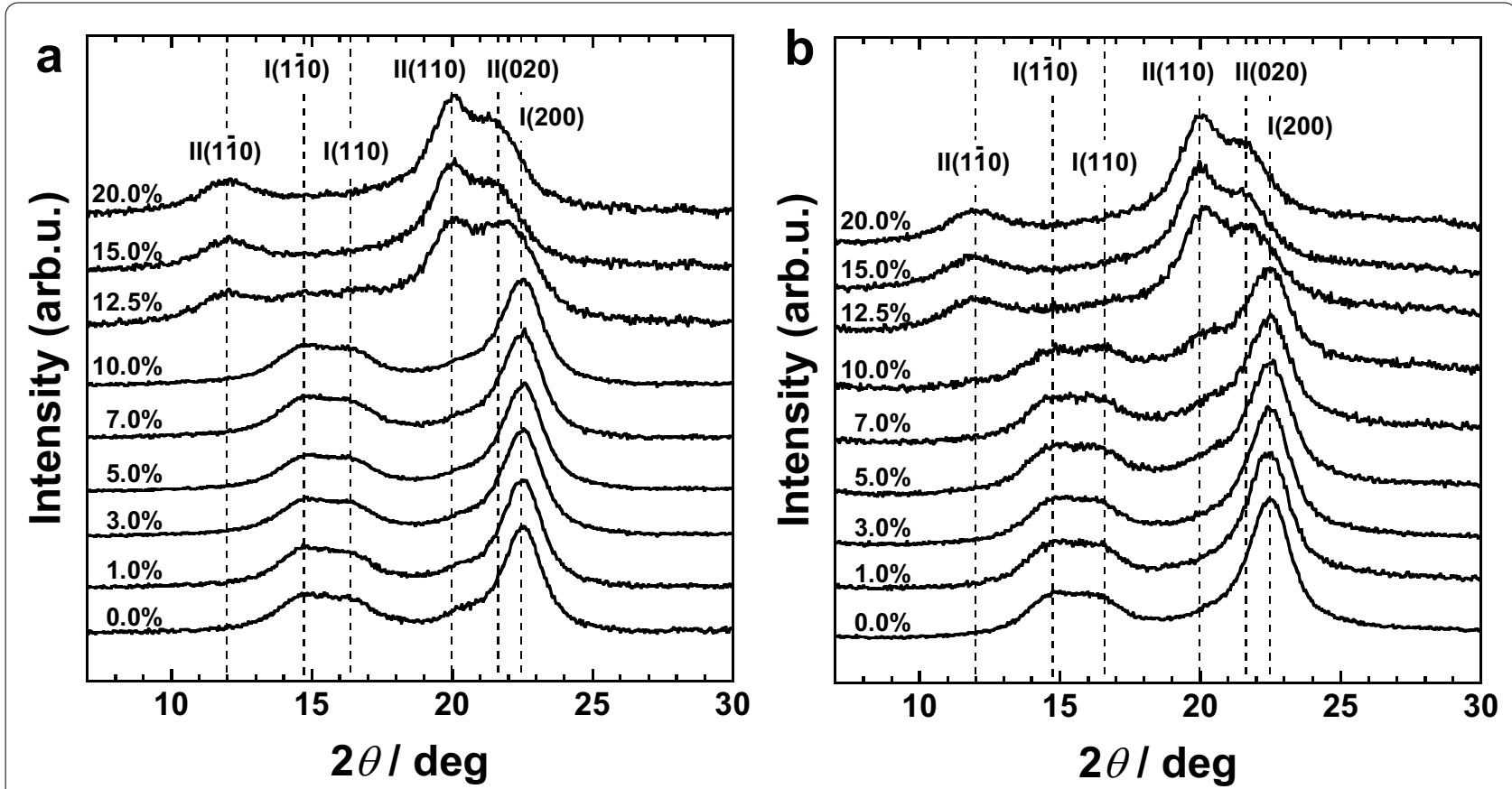

Fig. 1 WAXD profiles of a initial MCC powders and b ACC-CNFs treated with varying concentrations of aqueous $\mathrm{NaOH}$. $\mathrm{NaOH}$ concentration: 0.0 , $1.0,3.0,5.0,7.0,10.0,12.5,15.0$, and $20.0 \mathrm{wt} \%$

(CM-CNFs) were also measured via WAXD under the same conditions.

Peak separation of the WAXD profiles [26-28] was conducted based on the second derivative of the profile data using the spectral data processing software GRAMS/AI (Thermo Fischer Scientific, Inc. USA), prior to the following calculations. The crystallinity and the extent of transformation into cellulose II (Cellulose II ratio (\%)) were calculated from the WAXD profiles $(n=3-5)$ according to previous references [27, 29-31]:

$$
\begin{aligned}
& \text { Crystallinity } / \% \\
& =\text { (total areas of typical diffraction peaks } \\
& \text { from cellulose I and cellulose II } \\
& / \text { total areas of crystalline and amorphous peaks }) \\
& \times 100, \\
& \text { Cellulose II ratio / } \% \\
& =\text { (total areas of typical three diffraction } \\
& \text { peaks from cellulose II/total areas of cellulose I } \\
& \text { and cellulose II peaks }) \times 100 .
\end{aligned}
$$

\section{Fourier transform infrared (FT-IR) spectroscopy}

To undergo FT-IR measurements, the CM-CNFs were lyophilized and embedded into $\mathrm{KBr}$ pellets.
Measurements were performed using an FT-IR spectrophotometer equipped with a TGS detector (FT/IR-620, JASCO Corp., Tokyo, Japan). The accumulation number, resolution and wavenumber region of the measurements were 32 scans, $2 \mathrm{~cm}^{-1}$ and $400-4000 \mathrm{~cm}^{-1}$, respectively. All spectra were normalized using the band at $1162 \mathrm{~cm}^{-1}$, attributable to the $\mathrm{C}-\mathrm{O}$ stretching vibration of the cellulose backbone [32].

\section{Atomic force microscopy (AFM)}

At each treatment step, the size and morphology of the ACC-CNFs were observed by AFM (MFP-3D Origin; Oxford Instruments Asylum Research, Inc., Santa Barbara, CA, USA) using a silicon cantilever (OMCLAC160TS-R3; Olympus Corp., Tokyo, Japan). An aqueous dispersion of CNFs $\left(1.0 \times 10^{-3} \mathrm{wt} \%\right)$ was dropped onto a cleaved natural mica substrate (The Nilaco Corp., Tokyo, Japan), then dried at room temperature. The AFM measurements were operated in AC mode under ambient conditions.

\section{Conductivity titration}

The quantity of carboxy groups on the surface of the CM-CNFs was estimated using the conductivity titration method [33]. Water dispersions of CM-CNFs were adjusted to a $\mathrm{pH}$ of 3 or less using $\mathrm{HCl}$ in the presence 


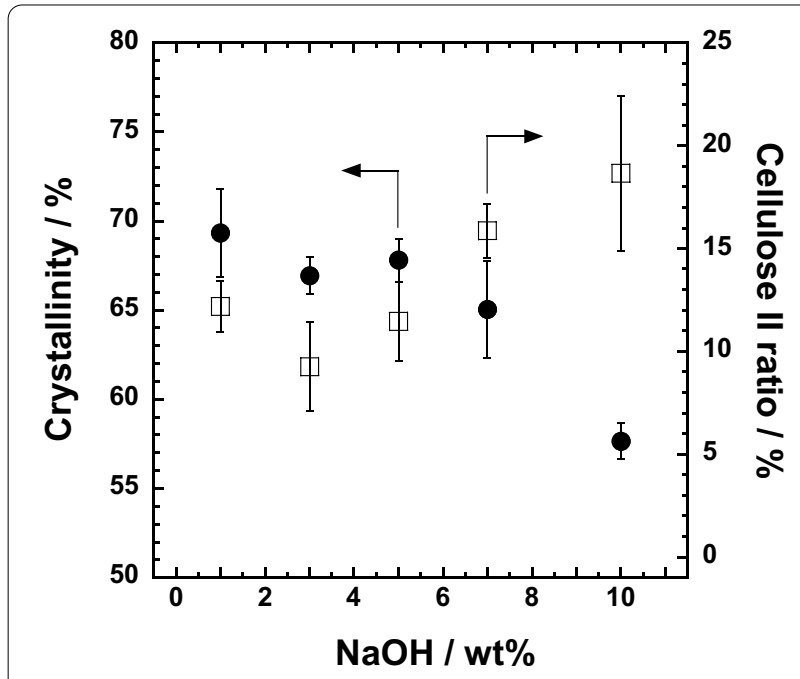

Fig. 2 Crystallinity (closed circles) and cellulose II ratio (open squares) calculated from WAXD profiles $(n=3-5$ ) of cellulose nanofibrils treated with aqueous $\mathrm{NaOH}$ solutions. $\mathrm{NaOH}$ concentration: 1.0, 3.0, 5.0, 7.0, and $10.0 \mathrm{wt} \%$

of $\mathrm{NaCl}$. The titration was performed with a $0.01 \mathrm{M}$ aqueous $\mathrm{NaOH}$ solution.

\section{Sedimentation test}

Water dispersions of ACC-CNFs and CM-CNFs were adjusted to $\mathrm{pH} 4,7$ and 10 prior to shaking for $30 \mathrm{~min}$

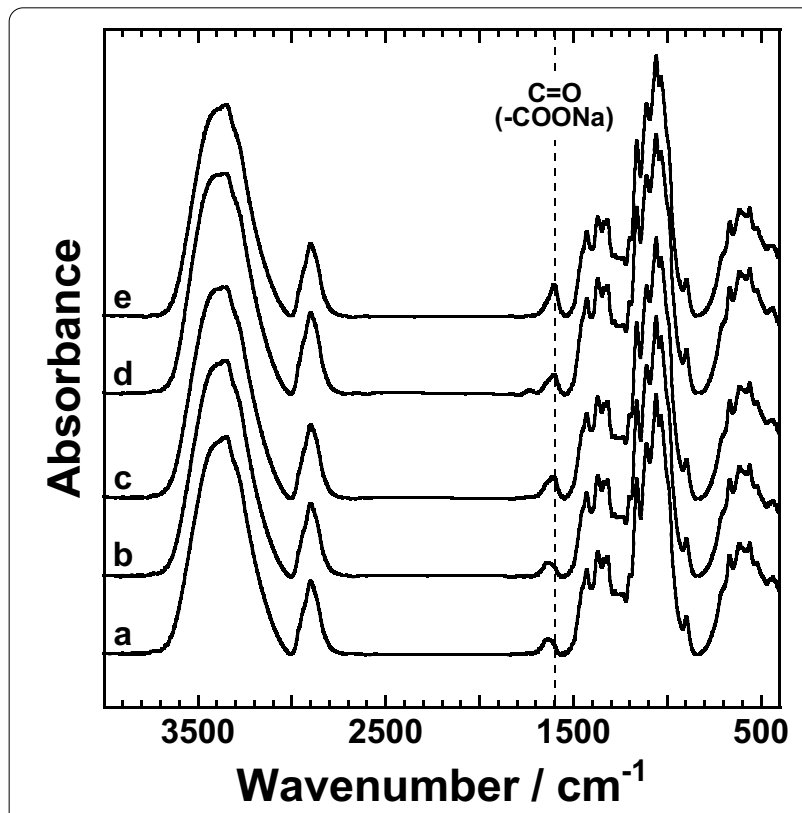

Fig. 3 FT-IR spectra of cellulose nanofibrils derivatized through carboxymethylation after alkali-activation with different $\mathrm{NaOH}$ concentrations. $\mathrm{NaOH}$ concentrations: a 0.0 wt $\%$, b 1.0 wt $\%$, c 3.0 $w t \%$, d $5.0 w t \%$ and e $7.0 w t \%$, corresponding to Fig. $1 \mathrm{~b}$ at room temperature. Centrifugation $(500 \times g, 10 \mathrm{~min}$, $25{ }^{\circ} \mathrm{C}$ ) was used to compare the dispersion stability of each sample.

\section{Results and discussion}

Alkali-induced swelling of cellulose nanofibrils

ACC-CNFs were treated with $1-20$ wt\% aqueous $\mathrm{NaOH}$ solutions, and the extent of alkali-induced swelling of the nanofibrils was indirectly estimated from the transformation of the crystalline polymorphs. Figure 1a shows WAXD profiles of the raw materials of ACC-CNFs, namely MCC powders, in a dried state after rinsed with DI water following alkali treatment. The native cellulose I structure of the wood-based MCC was almost unchanged with up to $10 \mathrm{wt} \% \mathrm{NaOH}$. The cellulose II structure became dominant as crystal structure by alkali treatment at $12.5 \mathrm{wt} \% \mathrm{NaOH}$, while significant cellulose I structure was not observed over $15 \mathrm{wt} \% \mathrm{NaOH}$. Figure $1 \mathrm{~b}$ shows the WAXD profiles of the alkali-treated ACCCNFs. The original wood-based ACC-CNFs provided the reference diffraction pattern for a native cellulose I structure similar to MCC. Following alkali treatment with up to $10 \mathrm{wt} \% \mathrm{NaOH}$, the WAXD profiles show the appearance of shoulders and diffraction peaks attributable to the cellulose II crystal structure. With alkali treatment over $12.5 \mathrm{wt} \% \mathrm{NaOH}$, the intensity of these peaks stabilized, indicating that the ACC-CNF crystal structure had transformed from cellulose I to cellulose II. Thus, the structural transformation of ACC-CNFs was implied to be more sensitive to the alkali concentration than the case of microfibers.

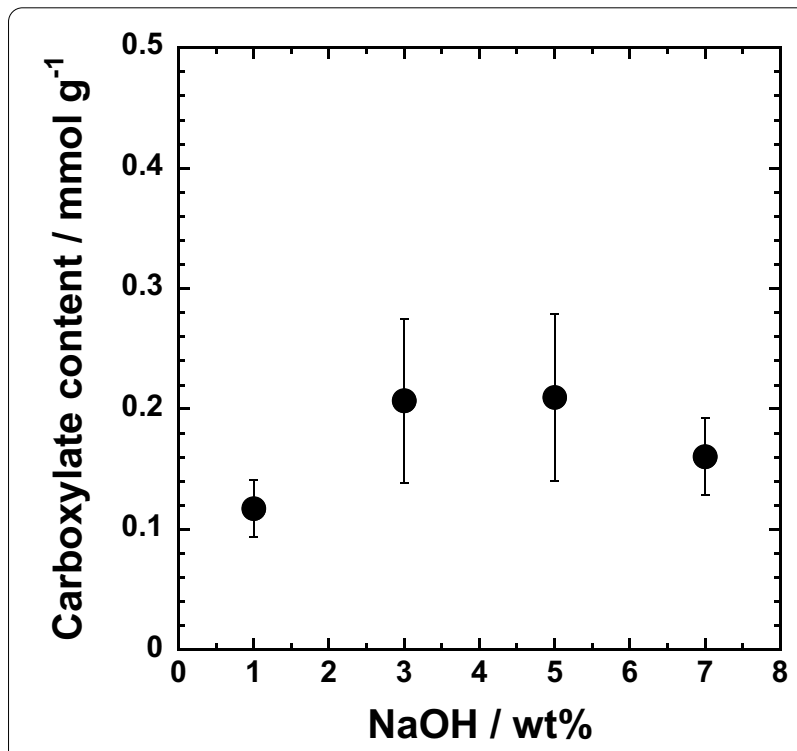

Fig. 4 Carboxylate content in CM-CNFs estimated by conductivity titration. Carboxymethylation was performed after alkali-activation with different $\mathrm{NaOH}$ concentrations 

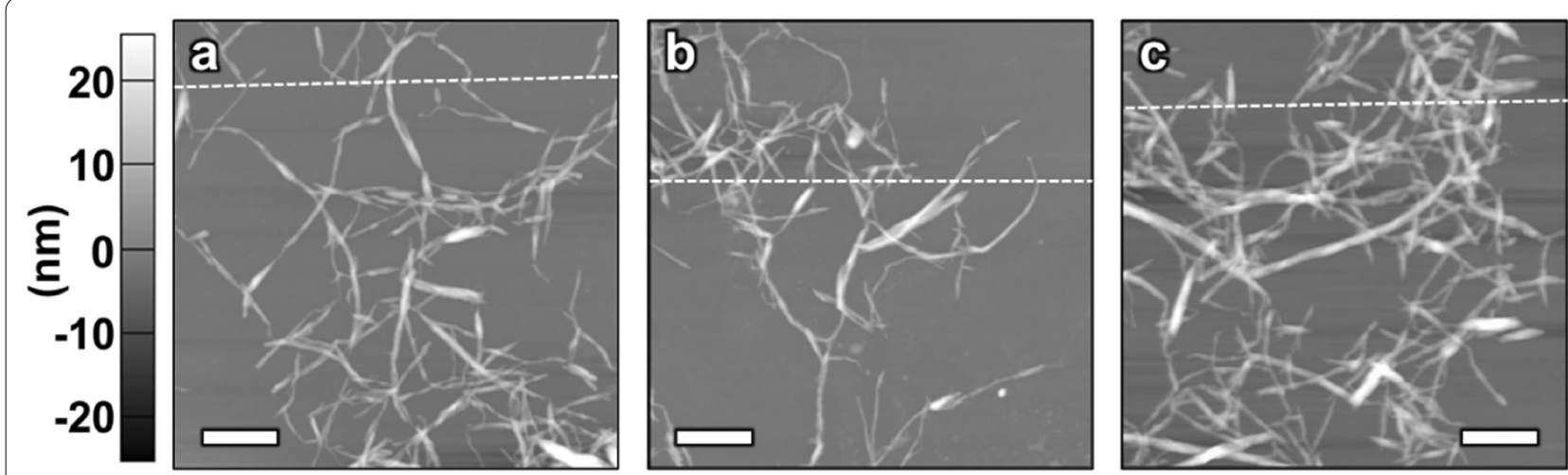

Fig. 5 AFM height images of a ACC-CNFs, b alkali-treated CNFs (7 wt\% NaOH) and c CM-CNFs. Scale bar $500 \mathrm{~nm}$

Table 1 Height and length values of ACC-CNFs, alkali-treated CNFs and CM-CNFs, calculated on the basis of their AFM images

\begin{tabular}{llll}
\hline & ACC-CNFs & Alkali-treated CNFs & CM-CNFs \\
\hline Height/nm & $8.4 \pm 4.7$ & $8.2 \pm 3.9$ & $8.3 \pm 4.1$ \\
Length/ $\mu \mathrm{m}$ & $0.93 \pm 0.55$ & $0.96 \pm 0.55$ & $0.93 \pm 0.37$ \\
\hline
\end{tabular}

a
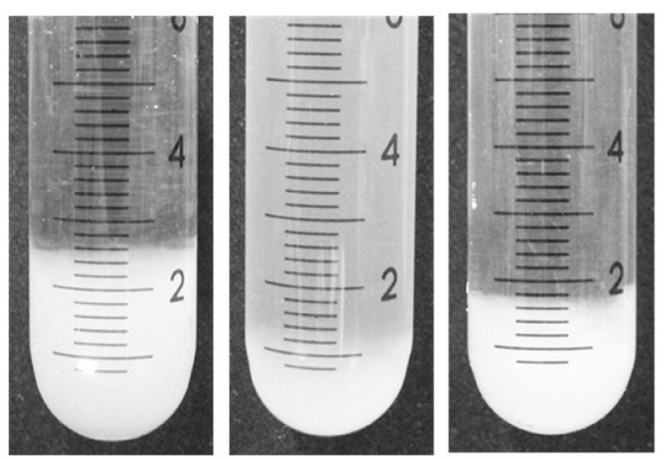

b
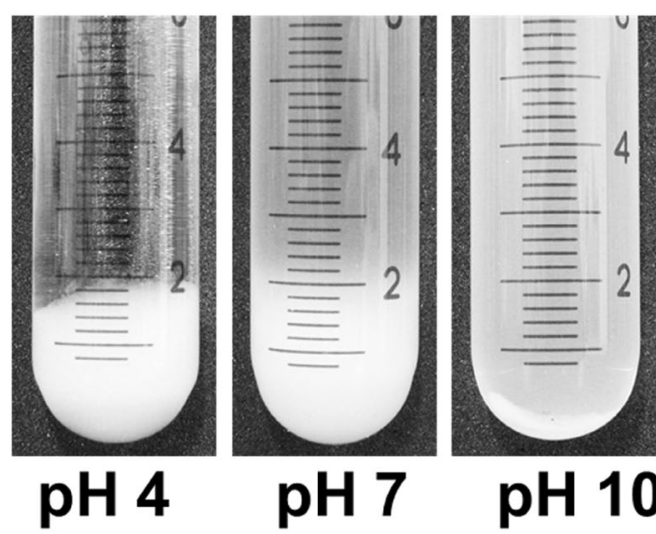

pH 7
Fig. 6 Photographs of CNF suspensions after centrifugation at $\mathrm{pH} 4$, 7 and 10: a unmodified CNFs, b CM-CNFs
Figure 2 shows the crystallinity and the proportion of cellulose II structure in the crystalline region, as calculated from the WAXD profiles of CNFs treated with less than $10 \mathrm{wt} \% \mathrm{NaOH}$ solution. When the $\mathrm{NaOH}$ concentration exceeded $7 \mathrm{wt} \%$, there was a significant decrease in the crystallinity and increase in the proportion of cellulose II structure present. These results indicate that the cellulose I structure at surface regions of the ACC-CNFs was partially transformed into the cellulose II structure [34]. The results also imply that the alkali-penetrated region of ACC-CNFs is sensitive to the $\mathrm{NaOH}$ concentration. According to previous studies [20, 23] regarding alkali treatment of plant fibers at low $\mathrm{NaOH}$ concentrations (less than ca. $10 \mathrm{wt} \%$ ), the hydroxide ions cannot fully penetrate the cellulose crystalline lattice because of size restrictions of the hydrated ions. Therefore, transformation of the crystal structure in entire cellulosic fibers is not likely to occur. The partial crystalline transition of ACC-CNFs at low concentrations of $\mathrm{NaOH}$ might be due to the large specific surface area of our material [11, 13]. Namely, treatment with $1-5 \mathrm{wt} \%$ of $\mathrm{NaOH}$ solution promoted conversion of the hydroxy groups into alkoxide groups only at the surface of the ACC-CNFs. Therefore, it was important to investigate the activation effect of the alkali treatment on surface chemical modification of the crystalline ACC-CNFs, as discussed in the following sections.

\section{Carboxymethylation of activated cellulose nanofibrils}

FT-IR spectra for the ACC-CNFs after the carboxymethylation reaction are shown in Fig. 3. The absorption band detected at $1603 \mathrm{~cm}^{-1}$ is attributable to the $\mathrm{C}=\mathrm{O}$ of the carboxylate [35]. The band intensity increased with increasing concentration of the $\mathrm{NaOH}$ used during the pre-treatment stage. The quantity of carboxymethyl 
(CM) groups introduced on the surface of the ACC-CNFs was estimated by a conductivity titration. When the pretreatment concentration of $\mathrm{NaOH}$ was over $3 \mathrm{wt} \%$, the quantity of CM groups increased (Fig. 4). These results suggest that the initial alkali treatment activated the reactivity of the hydroxy groups on the surface of ACC-CNFs, enhancing the introduction efficiency of the CM groups during subsequent carboxymethylation. However, higher concentrations of $\mathrm{NaOH}$ (over $10 \mathrm{wt} \%$ ) caused a significant transition of the crystal structure from cellulose I to cellulose II (see Figs. 1 and 2). Therefore, $3-7 \mathrm{wt} \%$ is a suitable alkaline concentration range for the surface activation of the ACC-CNFs. AFM measurements showed that the alkali pre-treatment and carboxymethylation had a negligible influence on the size and morphology of the ACC-CNFs (Fig. 5 and Table 1).

Sedimentation tests were performed to examine how dependent the introduction of CM groups was on the surface properties of the ACC-CNFs, as shown in Fig. 6. The aqueous dispersions of the untreated ACC-CNFs and CM-ACC-CNFs were centrifuged at $500 \times g$ for $10 \mathrm{~min}$ at $\mathrm{pH} 4,7$ and 10 . The untreated ACC-CNFs precipitated regardless of the $\mathrm{pH}$ (Fig. 6a). In contrast, the CM-ACC-CNFs appeared dispersed under basic conditions (Fig. 6b). This is presumably because of the increase in electrostatic repulsion between the negatively charged carboxylate groups $\left(\mathrm{p} K_{\mathrm{a}} 4.4\right)$ [36]. The aggregation and precipitation of CM-CNFs under acidic conditions are hypothesized to result from the formation of acidic carboxyl groups. These results indicate that the introduction of $\mathrm{CM}$ groups to the surface introduces $\mathrm{pH}$-responsive surface properties.

\section{Conclusions}

In this study, we investigated a simple and novel approach for the surface activation of ACC-CNFs under mild aqueous and alkaline conditions. Hydroxy groups were activated at the surface of the wood-derived ACCCNFs through partial swelling by mild alkali treatment with aqueous $\mathrm{NaOH}$ solutions. The extent of the subsequent $\mathrm{CM}$ derivatization of the ACC-CNF surface was dependent on the alkali-activation conditions, with 3 to 7 wt\% found as the optimum alkaline concentration range for surface activation. The introduction of $\mathrm{CM}$ groups to the ACC-CNF surface improved their dispersibility in water and simultaneously introduced $\mathrm{pH}$-responsive behavior. This is an exciting example of introducing a dynamic chemically modified surface onto CNFs. Overall, this facile activation treatment allowed for the subsequent chemical modification of the ACC-CNF surface under mild conditions, thus creating new opportunities for ACC-CNFs to be developed into functional bio-based materials.

\section{Abbreviations}

ACC: Aqueous counter collision; AFM: Atomic force microscopy; CM: Carboxymethyl(ated); CNFs: Cellulose nanofibrils; DI: Deionized; FT-IR: Fourier transform infrared; MCC: Microcrystalline cellulose; WAXD: Wide-angle X-ray diffraction.

\section{Acknowledgements}

We thank Mr. Koichiro Ishida (Kyushu University) for his support measuring the size and morphology of fibers.

\section{Authors' contributions}

SY: research plan throughout the study and preparation of the paper; AN: performing experiments; TK: research plan and preparation of the paper. All authors read and approved the final manuscript.

Funding

This work was supported by JSPS KAKENHI Grant Numbers 18 K05767 and 25712020.

Availability of data and materials

Not applicable.

\section{Declarations}

\section{Competing interests}

The authors declare that they have no competing interests.

Received: 30 November 2021 Accepted: 15 February 2022

Published online: 03 March 2022

\section{References}

1. Shimizu T (2002) Bottom-up synthesis and structural properties of selfassembled high-axial-ratio nanostructures. Macromol Rapid Commun 23:311-331. https://doi.org/10.1002/1521-3927(20020401)23:5/6\%3c311:: aid-marc311\%3e3.0.co;2-u

2. Mendes AC, Baran ET, Reis RL, Azevedo HS (2013) Self-assembly in nature: using the principles of nature to create complex nanobiomaterials. Wiley Interdiscip Rev Nanomed Nanobiotechnol 5:582-612. https://doi.org/10. 1002/wnan.1238

3. Fan YX, Wang YL (2018) Self-assembly and functions of star-shaped oligomeric surfactants. Langmuir 34:11220-11241. https://doi.org/10.1021/ acs.langmuir.8b00290

4. Palivan CG, Goers R, Najer A, Zhang XY, Car A, Meier W (2016) Bioinspired polymer vesicles and membranes for biological and medical applications. Chem Soc Rev 45:377-411. https://doi.org/10.1039/c5cs00569h

5. Walther A, Muller AHE (2013) Janus particles: synthesis, self-assembly, physical properties, and applications. Chem Rev 113:5194-5261. https:// doi.org/10.1021/cr300089t

6. Isogai A (2013) Wood nanocelluloses: fundamentals and applications as new bio-based nanomaterials. J Wood Sci 59:449-459. https://doi.org/10. 1007/s10086-013-1365-z

7. Saito T, Kuramae R, Wohlert J, Berglund LA, Isogai A (2013) An ultrastrong nanofibrillar biomaterial: the strength of single cellulose nanofibrils revealed via sonication-induced fragmentation. Biomacromol 14:248253. https://doi.org/10.1021/bm301674e

8. Nishino T, Matsuda I, Hirao K (2004) All-cellulose composite. Macromolecules 37:7683-7687. https://doi.org/10.1021/ma049300h

9. Kondo T, Morita M, Hayakawa K, Onda Y (2008) Polysaccharide wet pulverization method. US Patent 7357339-B2, 2008.

10. Kondo T, Kose R, Naito H, Kasai W (2014) Aqueous counter collision using paired water jets as a novel means of preparing bio-nanofibers. Carbohydr Polym 112:284-290. https://doi.org/10.1016/j.carbpol.2014.05.064 
11. Kose R, Mitani I, Kasai W, Kondo T (2011) "Nanocellulose" as a single nanofiber prepared from pellicle secreted by Gluconacetobacter xylinus using aqueous counter collision. Biomacromol 12:716-720. https://doi. org/10.1021/bm1013469

12. Tsuboi K, Yokota S, Kondo T (2014) Difference between bamboo- and wood-derived cellulose nanofibers prepared by the aqueous counter collision method. Nord Pulp Pap Res J 29:69-76. https://doi.org/10.3183/ npprj-2014-29-01-p069-076

13. Tsuji T, Tsuboi K, Yokota S, Tagawa S, Kondo T (2021) Characterization of an amphiphilic janus-type surface in the cellulose nanofibril prepared by aqueous counter collision. Biomacromol 22:620-628. https://doi.org/10. 1021/acs.biomac.0c01464

14. Kose R, Kasai W, Kondo T (2011) Switching surface properties of substrates by coating with a cellulose nanofiber having a high adsorbability. Sen-i Gakkaishi 67:163-168. https://doi.org/10.2115/fiber.67.163

15. Yokota S, Kamada K, Sugiyama A, Kondo T (2019) Pickering emulsion stabilization by using amphiphilic cellulose nanofibrils prepared by aqueous counter collision. Carbohydr Polym 226:115293. https://doi.org/10.1016/j. carbpol.2019.115293

16. Ishikawa G, Tsuji T, Tagawa S, Kondo T (2021) Adsorption of Janus-type amphiphilic cellulose nanofibrils onto microspheres of semi-crystalline polymers. Macromolecules 54:9393-9400. https://doi.org/10.1021/acs. macromol.1c01163

17. Ishida K, Yokota S, Kondo T (2021) Localized surface acetylation of aqueous counter collision cellulose nanofibrils using a Pickering emulsion as an interfacial reaction platform. Carbohydr Polym 261:117845. https://doi. org/10.1016/j.carbpol.2021.117845

18. Yokota S, Tagawa S, Kondo T (2021) Facile surface modification of amphiphilic cellulose nanofibrils prepared by aqueous counter collision. Carbohydr Polym 255:117342. https://doi.org/10.1016/j.carbpol.2020. 117342

19. Brumer H, Zhou Q, Baumann MJ, Carlsson K, Teeri TT (2004) Activation of crystalline cellulose surfaces through the chemoenzymatic modification of xyloglucan. J Am Chem Sco 126:5715-5721. https://doi.org/10.1021/ ja0316770

20. Gallego R, Piras CC, Rutgeerts LAJ, Fernandez-Prieto S, De Borggraeve WM, Franco JM, Smets J (2020) Green approach for the activation and functionalization of jute fibers through ball milling. Cellulose 27:643-656. https://doi.org/10.1007/s10570-019-02831-0

21. Huang L, Wu Q, Wang QW, Wolcott M (2019) One-step activation and surface fatty acylation of cellulose fibers in a solvent-free condition. ACS Sustain Chem Eng 7:15920-15927. https://doi.org/10.1021/acssuschem eng.9b01974

22. Jahn A, Schroder MW, Futing M, Schenzel K, Diepenbrock W (2002) Characterization of alkali treated flax fibres by means of FT Raman spectroscopy and environmental scanning electron microscopy. Spectrochim Acta A Mol Biomol Spectrosc 58:2271-2279. https://doi.org/10.1016/ s1386-1425(01)00697-7

23. Liu YP, Hu H (2008) X-ray diffraction study of bamboo fibers treated with $\mathrm{NaOH}$. Fibers Polym 9:735-739. https://doi.org/10.1007/ s12221-008-0115-0

24. Huan SQ, Yokota S, Bai L, Ago M, Borghei M, Kondo T, Rojas OJ (2017) Formulation and composition effects in phase transitions of emulsions costabilized by cellulose nanofibrils and an ionic surfactant. Biomacromol 18:4393-4404. https://doi.org/10.1021/acs.biomac.7b01452

25. Heydarzadeh HD, Najafpour GD, Nazari-Moghaddam AA (2009) Catalystfree conversion of alkali cellulose to fine carboxymethyl cellulose at mild conditions. World Appl Sci J 6:564-569

26. Wang $Y$, Zhao YL, Deng YL (2008) Effect of enzymatic treatment on cotton fiber dissolution in $\mathrm{NaOH} /$ urea solution at cold temperature. Carbohydr Polym 72:178-184. https://doi.org/10.1016/j.carbpol.2007.08.003

27. Garvey CJ, Parker IH, Simon GP (2005) On the interpretation of X-ray diffraction powder patterns in terms of the nanostructure of cellulose I fibres. Macromol Chem Phys 206:1568-1575. https://doi.org/10.1002/ macp.200500008

28. Cao Y, Tan HM (2005) Study on crystal structures of enzyme-hydrolyzed cellulosic materials by X-ray diffraction. Enzyme Microb Technol 36:314-317. https://doi.org/10.1016/j.enzmictec.2004.09.002

29. Hult LE, Iversen T, Sugiyama J (2003) Characterization of the supramolecular structure of cellulose in wood pulp fibres. Cellulose 10:103-110. https://doi.org/10.1023/A:1024080700873
30. Park S, Baker JO, Himmel ME, Parilla PA, Johnson DK (2010) Cellulose crystallinity index: measurement techniques and their impact on interpreting cellulase performance. Biotechnol Biofuels 3:10. https://doi.org/10.1186/ 1754-6834-3-10

31. Mansikkamaki P, Lahtinen M, Rissanen K (2007) The conversion from cellulose I to cellulose II in $\mathrm{NaOH}$ mercerization performed in alcohol-water systems: an X-ray powder diffraction study. Carbohydr Polym 68:35-43. https://doi.org/10.1016/j.carbpol.2006.07.010

32. Liang CY, Marchessault RH (1959) Infrared spectra of crystalline polysaccharides. II. Native celluloses in the region from 640 to $1700 \mathrm{~cm}^{-1}$. J Polym Sci 39:269-278. https://doi.org/10.1002/pol.1959.1203913521

33. Saito T, Isogai A (2004) TEMPO-mediated oxidation of native cellulose. The effect of oxidation conditions on chemical and crystal structures of the water-insoluble fractions. Biomacromol 5:1983-1989. https://doi.org/10. 1021/bm0497769

34. Okano T, Sarko A (1985) Mercerization of cellulose. II. Alkali cellulose intermediates and a possible mercerization mechanism. J Appl Polym Sci 30:325-332. https://doi.org/10.1002/app.1985.070300128

35. Pushpamalar V, Langford SJ, Ahmad M, Lim YY (2006) Optimization of reaction conditions for preparing carboxymethyl cellulose from sago waste. Carbohydr Polym 64:312-318. https://doi.org/10.1016/j.carbpol. 2005.12.003

36. Song JL, Birbach NL, Hinestroza JP (2012) Deposition of silver nanoparticles on cellulosic fibers via stabilization of carboxymethyl groups. Cellulose 19:411-424. https://doi.org/10.1007/s10570-011-9647-3

\section{Publisher's Note}

Springer Nature remains neutral with regard to jurisdictional claims in published maps and institutional affiliations.

\section{Submit your manuscript to a SpringerOpen ${ }^{\circ}$ journal and benefit from:}

- Convenient online submission

- Rigorous peer review

- Open access: articles freely available online

- High visibility within the field

- Retaining the copyright to your article

Submit your next manuscript at $\boldsymbol{\nabla}$ springeropen.com 